\title{
Tres Constructores de Obras Científico-Técni- cas de Minería y Metalurgia en la Nueva España del Siglo XVII: Luis Berrio de Montalvo, Jerónimo de Becerra y Juan del Corro
}

\author{
María Luisa Rodríguez-Sala \\ Instituto de Investigaciones Sociales, \\ Universidad Nacional Autónoma de México (UNAM)
}

A partir de un análisis histórico-social de tres autores de obra impresa de minería y metalurgia consideramos que esos personajes contribuyeron a la conformación y desarrollo de la ciencia y la técnica en México en un espacio y escenario particulares: el México colonial del siglo XVII. En ellos justificamos la existencia de estamentos ocupacionales que existieron durante los dos primeros siglos novohispanos y que derivaron, paulatinamente, en las comunidades profesionales y científicas de sucesivos espacios temporales. En el análisis de los personajes ponemos de manifiesto la existencia de rasgos característicos de conformación de una ciencia nacional. Fueron éstos, incipientes en las primeras etapas, y se dieron, fundamentalmente, a través de la vinculación de la ciencia y la técnica con la búsqueda de solución a los problemas de la naciente sociedad novohispana, a la domesticación de las tendencias científicas y técnicas europeas a las necesidades de la nueva sociedad y a la incorporación de las contribuciones autóctonas a la ciencia europea.

Este trabajo forma parte de un proyecto más amplio, "Personajes y Escenarios Espacio-Temporales en la Construcción de la Actividad Científica-Técnica Nacional". ${ }^{1}$ En esa investigación partimos del análisis histórico-social de los personajes que contribuyeron con su obra escrita a la conformación y desarrollo de la ciencia y la técnica en México en diferentes espacios temporales, desde la etapa colonial hasta el México contemporáneo. Buscamos justificar la actuación de los autores de obra publicada en diferentes tipos y escenarios de organización social, los cuales, a partir de la existencia de estamentos ocupacionales durante los dos primeros siglos coloniales, derivaron, paulatinamente, en las comunidades profesionales y científicas de sucesivos espacios temporales. En todos ellos propugnamos

1 Se desarrolla en el Instituto de Investigaciones Sociales con auspicio financiero del Programa PAPIIT de la Dirección General de Asuntos del Personal Académico de la UNAM. 
por poner de manifiesto la existencia de los rasgos característicos de conformación de una ciencia nacional. Fueron éstos incipientes en las primeras etapas y se dieron, fundamentalmente, a través de la vinculación de la ciencia y la técnica con la búsqueda de solución a los problemas de la naciente sociedad novohispana, a la domesticación de las tendencias científicas y técnicas europeas a las necesidades novohispanas, así como a la incorporación de las contribuciones autóctonas a la ciencia europea. Estos rasgos iniciales devinieron, en las siguientes etapas de desarrollo social y económico, en auténticos y originales aportes de una actividad científica y técnica producida en el escenario de finales de la etapa colonial y de los sucesivos espacios y escenarios de la sociedad mexicana independiente y contemporánea.

Ha sido así cómo, a partir del conocimiento de las actividades, la vida y las contribuciones científicas y/o técnicas de los personajes que nos legaron obra impresa, y, fundamentalmente, mediante la consulta de fuentes primarias, podemos, paulatinamente, conocer los tipos de organización social en que se movieron y la dinámica que daría lugar a una evidente ciencia novohispana.

En la presente investigación analizamos esas características solamente para aquellos personajes que, durante el siglo XVII, produjeron obra impresa en el campo de la minería y la metalurgia. En algunos otros trabajos hemos estudiado los aportes de los letrados en el ámbito de otras áreas del conocimiento, en particular a la ciencia jurídica y a la técnica empleada en las obras del desagüe de la ciudad de México. ${ }^{2}$ En uno más, el de los técnicos y científicos vinculados con la astronomía y la astrología. ${ }^{3}$

\section{La temática minera en la Nueva España}

Durante el siglo XVI no se publican, que esté registrado en las bibliografías, obras sobre minería, si bien no hay duda acerca del desarrollo práctico de esa actividad a lo largo del primer siglo colonial. Durante ese periodo se colocan los fundamentos para el desenvolvimiento social y

2 Rodríguez-Sala, María Luisa: Escenarios y Personajes en la Construcción de la Ciencia y la Técnica: Letrados-juristas y Letrados-técnicos, Siglos XVI y XVII (en proceso de publicación).

3 Rodríguez-Sala, María Luisa: El Eclipse de Luna, Una Misión Científica de Felipe II en la Nueva España, Huelva, 1998. 
económico de esa rama de la actividad. Se dio esto, por un lado, a través de las exploraciones y descubrimientos de minas y el establecimientos de nuevos reales y, por otro, a partir de la enorme y significativa aportación técnica de Bartolomé de Medina al beneficio de la plata y su mayor y mejor aprovechamiento, procedimiento que fue adoptado y aplicado no sólo en la estructura minera de la Nueva España, también en el resto de las colonias españolas de ultramar. Pero, a pesar del enorme aporte de Bartolomé de Medina al incremento de la explotación minera, este experto no dejó documento escrito alguno. Y, de acuerdo a la delimitación metodológica de este proyecto de investigación, que parte de considerar, en esta etapa, exclusivamente a los constructores de la ciencia y la técnica nacionales que legaron obra impresa, no incluimos en este trabajo el estudio sobre Bartolomé de Medina, si bien ya ha sido incipientemente estudiado por nosotros en otro momento del desarrollo de nuestra línea de investigación. ${ }^{4}$

Durante el siglo XVII y a lo largo del periodo que cubre esta investigación, 1600 a 1685, solamente figuran tres personajes como autores de obras vinculadas con aspectos de la minería y la metalurgia. En la vida y obra del primero de ellos, don Luis de Berrio y Montalvo, encontramos, de nuevo, uno de los rasgos característicos de los letrados que desarrollaron sus actividades en la Nueva España de los dos primeros siglos coloniales: su vinculación con problemas que emergieron de esa sociedad en formación. En otros trabajos de investigación hemos analizado la participación de los letrados en la búsqueda de solución a la problemática que significó el desagüe de la ciudad capital y las derivaciones que de esas tareas se centraron en conocimientos técnicos y científicos.

El presente artículo está dedicado a analizar, en su primera parte, el aporte que uno de los miembros del estamento de los letrados dio a la construcción de la técnica minera y el saber metalúrgico. En la segunda, las contribuciones que provinieron de otros dos autores, no letrados, un médico y un militar. En los tres casos buscaremos las repercusiones de sus libros en la actividad minera novohispana.

Presentamos los estudios de la vida y obra de los tres personajes en el orden cronológico que marca el año de impresión de su primera obra publicada. Es así como el primero de ellos lo fue:

4 Rodríguez-Sala, María Luisa: "Bartolomé de Medina" en: Raíces de la Cultura Científica Nacional: Los primeros personajes en la Nueva España. Siglo XVI, México, D.F., 1994, págs. 168-181. 


\section{Luis Berrio de Montalbo}

De acuerdo a la bibliografía que hemos consultado sobre el tema minero podemos asegurar que las fuentes primarias localizadas para esta investigación no han sido, hasta ahora, analizadas y expuestas en la amplitud que lo hacemos ahora. ${ }^{5}$ De aquí que consideremos de utilidad para la construcción de la ciencia y técnicas novohispanas contribuir con un amplio análisis de la vida y obra de este personaje, el cual se ubica, sin duda alguna, como un funcionario y técnico a la medida de los requerimientos que exigía el funcionamiento del estamento de los letrados que prestaban sus servicios en el ámbito colonial. Si bien se trató de funcionarios de alto rango que estaban totalmente sujetos a las normas de la administración central metropolitana, el rasgo que los distingue y ubica en la construcción de una ciencia o técnica novohispanas y, por lo tanto, raíz de la nacional, es su grado de inserción en el contexto social en el que realizaban sus tareas, manifiesto por la búsqueda de solución a problemáticas surgidas en esa sociedad.

\section{Antecedentes en España}

Don Luis fue español. Nació en 1597 según información propia, ${ }^{6}$ muy probablemente en Osuna o en Sevilla, y realizó sus estudios de bachiller en cánones en la Universidad de Osuna y de licenciado en la de Sevilla. ${ }^{7}$ Como todos los letrados, inició su actividad profesional en la metrópoli. Su primer nombramiento fue el de oidor en la Audiencia de Sevilla; su desempeño en ese cargo le confirió la experiencia que más tarde le valdría ascensos en la administración novohispana. Según palabras de su hijo Luis, en la Audiencia sevillana, su padre:

“...defendió muchos pleitos y causas con gran opinión y aprobación de todos, haciendo muchas informaciones en derecho, y en particular un tratado en defensa de la dicha

5 Nuestro análisis está basado en los ricos materiales encontrados en el Archivo General de Indias de Sevilla (AGI, en adelante), complementados con los del Archivo General de la Nación de México (AGN, en adelante). Algunas fuentes también las ha estudiado Manuel Castillo Martos en su artículo: "Minería y metalurgia de azogue en la Nueva España (siglo XVII)", QUIPU, Revista Latinoamericana de Historia de las Ciencias y la Tecnología, vol. 12, núm. 1, México, enero-abril de 1999, págs.7-24.

6 AGI, México, 264.

7 AGI, Indiferente, 120, n. ${ }^{\circ}$ 101: "Relación de los servicios del capitán don Luis de Verrio y de los del licenciado Don Luis de Verrio Montalvo, su Padre, oidor que fue de la Audiencia de México". 
ciudad y de una provisión en que hizo un memorial de las casas de ella para repartirles el gasto del reparo de sus murallas para defensa de las avenidas del Río..." ${ }^{8}$

En el año de 1627, el conde de Puebla lo nombró alcalde mayor de justicia de la Villa de Constantina, cercana a la capital andaluza, "en donde prendió muchos delincuentes y castigó pecados públicos, y hizo otros servicios de importancia..." Dos años más tarde fue teniente de asistente de Sevilla y estuvo en el cargo más de cinco años, ejerciéndolo:

“...con la aprobación del Consejo Real de Castilla, hasta abril de 1634 con mucha aprobación, hallándose en muchos cabildos, presidiendo en la Ciudad en muchas ausencias y ocupaciones del Asistente, donde hubo grande concurso de negocios, y prendió a algunos que falseaban la moneda y acudió al Gobierno de la Ciudad...trabajó mucho con aprobación del Asistente, Ciudad y su Audiencia, pidió un donativo en Triana y juntó cantidad considerable que depositó en poder del depositario de él; remedió algunos incendios, defendió la jurisdicción Real...”.

No sólo desempeñó su propio cargo, también lo hizo con el de un compañero ausente. Recibió el reconocimiento del asistente de Sevilla, que lo era, para el año de 1634, el conde de Salvatierra, quien más tarde sería virrey de la Nueva España y se convertiría en su benefactor durante su largo periodo al frente del reino novohispano. ${ }^{10}$ Fue sólo después de haber comprobado su capacidad como abogado y administrador y haber sido "declarado buen juez en su residencia", cuando fue promovido a un nuevo cargo, ahora en el Nuevo Mundo, el de alcalde del crimen de la Real Audiencia de la Ciudad de México.

Don Luis pasó a la Nueva España a principios de 1636 y se le autorizó a embarcarse en Sanlúcar de Barrameda o en Cádiz. Su licencia de embarque acredita algunos datos familiares, entre otros que su madre se llamó doña Jerónima de Montalbo y que se le autorizó a llevar consigo:

"A doña Beatriz de Flores su mujer y a

Don Luis y Don Pedro Berrio, sus hijos pequeños.

Doña Beatriz de Montalbo, tía del dicho Alcalde, natural de esta ciudad, hija de Juan Belez de Montalbo y de Doña Catalina de León,

Laura Jacinta, criada, natural de Sevilla, hija de Pedro de Bornega y de Ana de Miguel, Martín Ibáñez de Ochandiano, criado, natural de la Villa Real de Alava, hijo de Pedro Ibáñez de Ochandiano y de María Ruíz de Arvinegui,

8 Ibídem, fol. 2

9 Ibídem, fol. 2.

10 García Sarmiento de Sotomayor, conde de Salvatierra, fue virrey desde el 23 de noviembre de 1642 al 13 de mayo de 1648 . 
Francisco de Soto, natural de Balboa, feligresía de Santa María de la Mar, diócesis de Orense, hijo de Bartolomé de Soto y de Francisca López,

Juan Sánchez de Tobar, natural de la Villa de Auñón, hijo de Felipe Sánchez Tobar y de Inés Sánchez.

Doña Victoria de León, natural de Lucena, mujer de Juan de Tobar, hija de Cristóbal de León y de doña Elvira Clavijo y Montenegro,

Las cuales dichas seis personas se despacharon a la provincia de Nueva España, la dicha doña Beatriz de Montalbo por la tía abuela del dicho Alcalde y los demás por solteros y criados suyos y de su mujer y los de Juan Sánchez Tobar y doña Victoria de León y las cuales, por cédula de S.M. y nombramiento de criados, se despachen en cualquiera nao de la flota". ${ }^{11}$

En reconocimiento a los servicios que había prestado a la judicatura y administración metropolitanas recibió su nuevo nombramiento real, que dice, en parte de su texto:

"Don Phelipe....teniendo consideración a la suficiencia y buenas letras de Vos, el licenciado Don Luis Berrio Montalvo y lo que me habéis servido y espero lo haréis, he tenido por bien y es mi merced que agora y de aquí adelante cuanto mi voluntad fuere, seáis mi alcalde de crimen de mi Audiencia Real de la Ciudad de México de la Nueva España en lugar y por promoción de el Doctor Don Matías de Peralta a la plaza de oidor que ha vacado en la Audiencia por jubilación del Doctor Lorenzo de Terrones y que como tal mi alcalde de ella podáis celebrar, conocer y determinar todos los pleitos y causas criminales que vinieren y están comenzados ante mis alcaldes de la dicha Audiencia...". ${ }^{2}$

Se le pidió rindiera el juramento acostumbrado ante la Audiencia de México. Su sueldo anual le fue fijado en ochocientos mil maravedíes. Se le pagaría por los oficiales de la Real Hacienda de la ciudad de México en los mismos tiempos que se pagaba a los otros alcaldes del crimen. Berrio disfrutaría de su salario desde el día que se hiciera a la vela en alguno de los puertos de Sanlúcar de Barrameda o Cádiz. Como era usual, hizo los pagos correspondientes a la "media annata" aún en España.

\section{Como letrado en la Nueva España}

Don Luis y su familia debieron haber llegado a su nueva residencia probablemente hacia mediados de 1636 y de hecho inició su desempeño administrativo y jurídico como alcalde del crimen en agosto de ese año, si bien había sido el 30 de octubre del año anterior cuando se le expidió su nombramiento en San Lorenzo el Real.

11 AGI, Contratación, 5539, L 5, fols. 253v.-254, del 19 de febrero de 1636, fols. 253v. y 254r.

12 AGI, Indiferente, 120, n. ${ }^{\circ}$ 101: "Relación de los servicios...", fols. 1-3. 
Por entonces el escenario novohispano ${ }^{13}$ presentaba estas características: desde 1633 se habían acrecentado las actividades de los piratas holandeses y en noviembre de 1634 una real cédula prohibió el comercio con el Perú. Los indios seguían muriéndose, no sólo por el azote del cocoliztli y otras epidemias, también por situaciones coyunturales, como las inundaciones de la capital y las sequías en el Septentrión y, con frecuencia, por explotación humana en reales de minas, haciendas y otros enclaves. El abastecimiento de mercurio para las minas de plata escaseaba más que nunca; pero, sin embargo, muchos naturales trabajaban en las minas como asalariados e inclusive, en ciertas regiones, como en el Septentrión, disfrutando de ciertos privilegios en la extracción del mineral, como la pepena, que les permitía obtener ciertas ganancias. En 1638, el virrey marqués de Cadereyta escribió al Consejo de Hacienda su preocupación por la carencia de azogue. Como veremos, Berrio también la percibió y como buen funcionario real a la medida de los intereses metropolitanos, pero también locales, parte de su quehacer como administrador y empresario en ciernes fue procurar reducir esta preocupante situación que afectaba en buena medida el desarrollo de la principal actividad económica de la Nueva España. Una de las medidas financieras más importantes de la época fue la que, a partir de 1637, con antecedentes desde 1626, se relacionó con la recaudación de fondos para el funcionamiento de la Armada de Barlovento y Seno Mexicano, destinada a proteger las costas del Caribe y del sureste mexicano: Yucatán, Campeche, Tabasco y Veracruz, con una cantidad nada insignificante, sobre los $200 \mathrm{mil}$ pesos anuales y que, en gran medida, procedían de impuestos, pero también de ganancias mineras. El cabildo de la ciudad de México tomó sus providencias a fin de preservar, para las obras de su desagüe, las tasas impositivas que provenían del vino y que se recaudaban en la ciudad capital y cinco leguas en su contorno, las cuales no deberían ser destinadas a completar los dineros que cubrirían las cuotas para la Armada de Barlovento.

También hacia los años treinta del siglo XVII, el cabildo y regimiento de la ciudad capital expuso al virrey los grandes problemas que aquejaban a la Nueva España y que estaban, entre sí, estrechamente relacionados. Por supuesto el cabildo consideró de primordial importancia la difícil situación de la ciudad, cuya pérdida repercutiría en el resto del reino a partir de un centralismo imperante y efectivo, de ahí que situara como primer problema

13 Este marco contextual fue elaborado para este trabajo por el becario colaborador, maestrante en historia, Fernando González Dávila basándose en Jonathan Israel, Clases sociales y vida política en México, México, 1980, y ampliado con aportes de la autora. 
el de la conservación y aseguramiento de la ciudad capital frente a sus inundaciones periódicas. El segundo, que en términos sociales, realmente, constituía el nuclear y fundamental, se centró en torno a la necesidad de sostener y conservar a la población indígena. Para aquella época y como lo fue durante toda la Colonia, eran los indios la base fundamental de las actividades económicas y, por lo tanto, de la riqueza del reino. De ellos escribe el cabildo: "son los indios quienes elaboran las minas de oro y plata y demás metales, cultivan las tierras, crían los ganados y son fielmente quienes benefician y cogen todos los géneros de que se compone toda la riqueza y sustento de la Nueva España". Preocupaba, especialmente en la capital, pero desde luego también en el resto de la Nueva España, la disminución de la población autóctona que se debía, principalmente, al desamparo en que se encontraba y que se centraba en la poca atención que se les brindaba a sus miembros en los siguientes aspectos: el excesivo consumo de bebidas alcohólicas, en términos generales lo que se conocía como "el chinguirito" y en la capital la ingestión del "tepache", que les debilitaba en una gran medida por "ser contrarias a su temperamento" y les exponía a enfermedades, las cuales, a su vez, no se atendían por carecer en los poblados indígenas de hospitales, médicos y medicinas; la falta de apoyo y socorro de los justicias, gobernadores y doctrineros y, por último, su muy escasa alimentación, pues "su comida es una tortilla de maíz y chile lo más ordinario". Como otro de los problemas graves se menciona la necesidad imperiosa de conservar el funcionamiento de las minas y el aumento de su producción, para lo cual se hacía indispensable resolver algunos problemas específicos, entre ellos, mantener a los indios en la explotación minera, dar a los mineros las concesiones por más de los dos años que entonces tenían y procurar que, quienes explotaran las minas tuvieran suficientes recursos económicos y pudieran contar con mayor cantidad de azogue. Finalmente, el último problema consistió en evitar el declive en que se encontraba la producción agraria, principalmente debido al retiro del repartimiento de indios a las haciendas agrícolas o "de panes" y al incremento en el precio de las semillas.

Este interesante reporte del estado del reino fue presentado por don Fernando Alfonso Carrillo, escribano mayor del cabildo metropolitano en su sesión del 21 de julio de 1636. "La ciudad", desde luego, se lo dio a conocer al virrey marqués de Cadereyta. ${ }^{14}$

14 Archivo Histórico del Ayuntamiento de la Ciudad de México, Libro Treinta de Actas Antiguas de Cabildo, México, 1908, págs. 172-176. 


\section{Sus tareas en la administración}

La labor de Berrio durante el tiempo que sirvió el cargo antes de ser promovido al de oidor en 1656 fue variada y de total entrega al servicio real como correspondía a todo miembro del estamento de los letrados. Durante los primeros años en su cargo inicial, el de alcalde del crimen, se dio cuenta de que en la práctica jurídica que se realizaba en la Real Audiencia se había establecido ya un vicio en los casos de competencia entre los jueces eclesiásticos y los civiles que defendían la jurisdicción real. Consistía en que los casos de reos refugiados en una iglesia quedaban sujetos a juicio sólo por juez eclesiástico sin dar parte al ordinario o civil y con ello se restaba injerencia a la jurisdicción real o civil. La preocupación de Berrio fue, desde luego, la de restablecer en la Nueva España la observancia de una aplicación jurídica correcta y ajustada a derecho. Debido a ello escribió directamente al rey, dándole a conocer la situación que existía en "esa, su Real Audiencia". Berrio insistió en que era conveniente contar con una cédula real que dejara en claro ambas jurisdicciones y así recomendó:

“...que cada una conforme a los sagrados cánones y leyes de los Reynos de Vuestra Majestad y la cédula real del 15 de abril de 1619 (que los eclesiásticos que están, sean absolutamente en su favor) conozcan que no se usurpe a la otra jurisdicción lo que le toca, que por esta causa queden los delitos sin castigo " .15

Debido a su oposición a que continuara este vicio jurídico y a las causas en las cuales había participado, Berrio fue excomulgado en 1638, si bien el castigo eclesiástico se le levantó por algunos días. En relación con esta situación personal, el alcalde del crimen insistió en "que los ánimos de la justicia real están tan amilanados que en muchos delitos alevosos de quiebra de mercaderes con grandes alzamientos, no se atreven a sacarlos de sus retraimientos".

En 1640, desempeñando el mismo puesto de alcalde de corte de lo criminal, Berrio presentó, durante el mes de mayo del mismo año, sus títulos para ser incorporados en la Real y Pontificia Universidad. Fue su padrino de incorporación el decano de la facultad y quedó como doctor de la institución después de haber jurado guardar los estatutos y defender la doctrina de la Inmaculada Concepción. ${ }^{16}$ Dos años más tarde, el 2 de julio, se incorporó a

15 AGI, México 75, r. 8, n. 41, del 17 de septiembre de 1638.

16 La Plaza y Jaén, Cristóbal de: Crónica de la Real y Pontificia Universidad de México, versión paleográfica, proemio, notas y apéndice de Nicolás Rangel, México, 1931, 2 volúmenes, libro IV, págs. 351 y 360 . 
la facultad de Cánones de la misma institución y, como era lo usual para los miembros de la Real Audiencia, no quedó sujeto a acto literario o académico alguno; sin embargo, sí ostentó el grado de doctor por esa Universidad.

Permaneció en el mismo cargo de alcalde de corte del crimen hasta que fue promovido al de oidor el 13 de septiembre de 1656. Durante ese lapso de 20 años gozó, simultáneamente, de varias comisiones. En su "relación de servicios y méritos" queda claro que:

“...Y habiendo pasado a la Nueva España, sirvió en la plaza de Alcalde del Crimen de la Audiencia de México desde agosto de 1636, llegando a ser el más antiguo y fue Auditor General de la Guerra en la Nueva España y los virreyes de ella le dieron diferentes comisiones en la Veracruz, y otras partes y para cobranzas de la Real Hacienda; fue Juez del Estado del Valle y sirvió a S.M. en la composición de las tierras y en los asientos de las alcabalas, naipes, papel sellado y otros, y fue Juez Administrador de todas las minas de la Nueva España y Juez del Pulque....". ${ }^{17}$

Su protector, el virrey García Sarmiento de Sotomayor, conde de Salvatierra, fue quien lo designó en el importante cargo de juez comisario, auditor general de la guerra y de la Armada de Barlovento. El nombramiento le fue expedido el 20 de diciembre de $1642{ }^{18}$ y en él queda claro que el cargo lo había dejado vacante don Pedro de Oros, quien pasó a habilitar la Caja de Zacatecas. Ante la necesidad de que fueran atendidos los asuntos pendientes en el juzgado de la guerra y, desde luego, "atendiendo a las partes de autoridad, letras y prudencia y las demás que concurren en la persona del dicho señor don Luis de Berrio y Montalvo" y al conocimiento que se tenía de su experiencia en tratar "causas y materia de la guerra" y su ya larga experiencia de diez años a la parte en oficios de justicia, tanto en España como en la Nueva España bajo las administraciones de varios virreyes, fue que el gobernante en funciones, conde de Salvatierra, le otorgó el nombramiento.

Durante el año de 1643 participó en su calidad de alcalde de corte en quince diferentes decisiones para que el virrey pudiera admitir las solicitudes de particulares y poblados de tierras y aguas, fijándoles el pago que deberían cubrir para poder gozar de esos derechos en sus posesiones de haciendas o poblaciones..$^{19}$ En el mismo año Berrio también participó para

17 AGI, Indiferente, 120, n. $^{\circ} 101$. de 1642.

18 AGN, Reales Cédulas Originales, vol. 49, exp. 187, fols. 172v.-174r. del 20 de diciembre

19 Ibídem, vol. 48, exps. 37, 47, 52, 53, 58, 62, 64, 68, 69, 71, 73, 77, 83, 89, 160, de agosto a diciembre de 1643 . 
determinar el monto que se debería asignar al oficio de receptor de la Real Audiencia, mismo que quedó vacante en diciembre de 1643 y se fijó en dos mil cuatrocientos pesos de oro común. ${ }^{20}$ Se trató en estos casos de actividades rutinarias, pero de una cierta significación económica y social.

Durante el último mes de 1643 el virrey conde de Salvatierra lo nombró juez del pulque de la ciudad de México y cinco leguas en su contorno. El disfrute de este cargo le otorgaba recibir los derechos que provenían de las condenas que permitían las ordenanzas y tenía la facultad de nombrar al escribano y alguacil correspondientes. Desde luego que tuvo que pagar la tasa impositiva de la media annata. ${ }^{21}$ Dos de sus comisiones consistieron en visitar a principios de 1644 las tierras del Marquesado del Valle de Oaxaca y de la villa de Cuernavaca, para constatar los descubrimientos de minas que se habían realizado en esos sitios y cuyas labores no se habían puesto en ejecución por pertenecer al "Señorío". En la misma ocasión se le comisionó para visitar y revisar las plantaciones de caña y otras plantas y el funcionamiento de los ingenios y trapiches que en ellas funcionaban..$^{22}$ Para junio del mismo año intervino en asuntos relacionados con los abastos de las carnicerías de la ciudad capital. ${ }^{23}$

\section{Sus actividades mineras y metalúrgicas}

El 22 de septiembre de 1643, Berrio fue designado juez administrador de las minas de la Nueva España por provisión real. Durante los siguientes meses de ese año debió haber conocido la existencia de unas olvidadas minas que se habían registrado en 1630 e hizo ensayar y probar el contenido de azogue "de sus metales". Los resultados de sus ensayos parecían prometer que eran ricas. Al respecto escribe el virrey, García Sarmiento de Montemayor, conde de Salvatierra:

“...de las cuales había sacado a razón de 18 onzas de azogue por quintal de piedra superficial que denotaban habían de ser dichas minas muy ricas de azogue en lo profundo donde se conjura con humedad y en su centro con menos en relación que la que causa el calor en la superficie..." ${ }^{24}$

20 Ibídem, vol. 48, exp. 148, fol. 59v.-174r. del 4 de diciembre de 1643.

21 Ibídem, vol. 48, exp. 164, fol. 63r. del 19 de diciembre de 1643.

22 - Ibídem, vol. 48, exps. 260 bis y 261, fols. 171v. y 172, del 23 y 25 de enero de 1644 .

23 Ibídem, vol. 48, exp. 324, fols. 220v.-221r., del 18 de junio de 1644.

24 AGI, México, 264: "Cartas y Expedientes sobre la Comisión para la fundación de las Minas de Azogue". 
Ya desde principios de 1644, Berrio manifestó un interés decidido en hacerse cargo de la explotación de esas minas de azogue, así como por experimentar su empleo en la extracción de la plata con ahorro de aquella materia prima. Al iniciarse ese año, el mismo virrey expresó ese interés de su protegido al escribir lo siguiente:

"...se demuestra el hecho de que el licenciado Berrio, alcalde del crimen, ha tomado particular cuidado y estudio y afecto, llevando a su casa a Pedro de Mendoza para facilitarle las experiencias para la extracción del metal con menor pérdida de azogue". ${ }^{25}$

En su carta el virrey explica que ha asistido a los experimentos en las minas y que por ello ha comisionado a Berrio para que, con su experiencia y conocimientos, asista a la continuación de las pruebas en las minas de Pachuca y Taxco. Fue en ese momento cuando don Luis adquirió conocimiento tanto de ciertos aspectos técnicos sobre el beneficio de la plata, como del funcionamiento de las minas. Este es el argumento fundamental que nos inclina a considerar que la obra que ha sido considerada como su primer trabajo impreso ${ }^{26}$ no fue tal, pues no pudo haber aparecido en la fecha que le asignan los bibliógrafos: 1634, año en que, por encontrarse en el servicio real como teniente del asistente en la ciudad de Sevilla, obviamente no conocía las minas de Taxco y tampoco había adquirido experiencia en la actividad minera. Sencillamente se trata o bien de un error tipográfico al invertir las dos segundas cifras del año de impresión (1643 por 1634), o bien no existió tal obra y el "Informe" es tan sólo parte de su libro fundamental de largo título. ${ }^{27}$ de $1644 "$

25 AGI, México, 75, r. 8, n. 41: "Carta del Virrey Conde de Salvatierra del 18 de enero

26 Berrio, Luis: Informe sobre las minas de Tasco y modo de beneficiarlas, México, 1634.

27 Al Exmo. Señor don García Sarmiento de Sotomayor y Luna Conde de Salbatierra, Marqués de Sobrosso, Señor, Su Virrey, Lugartheniente, Gobernador y Capitán General desta Nueva España y Presidente de la Audiencia y Chancilleria Real que en ella reside, etc. El licenciado Don Luys Berrio de Montalbo, Alcalde del Crimen en la dicha Real Audiencia, Corte y Chancillería de México, su Accessor Auditor General de la Guerra y Iuez Administrador de las minas deste Reyno. En informe del nuevo beneficio que se ha dado a los metales ordinarios de plata por azogue, y philosophia natural a que reduce el methodo y arte de la minería, para escusar a todos la perdida y consumido de azogue y a los antimoniosos, con las causas de que procede, que hasta hoy no se han alcanzado, de que resultara mayor ley de plata, y ahorro de costa, y poderse dar fundición a los metales secos sin perderse liga de plomo, ni el consumido ordinario de la greta o almartaga, en México, en la Imprenta del Secreto del Santo Oficio. Año de 1643. Por Francisco Robledo. En fol., 59 págs., 4 de principios y una de Îndice al fin. 


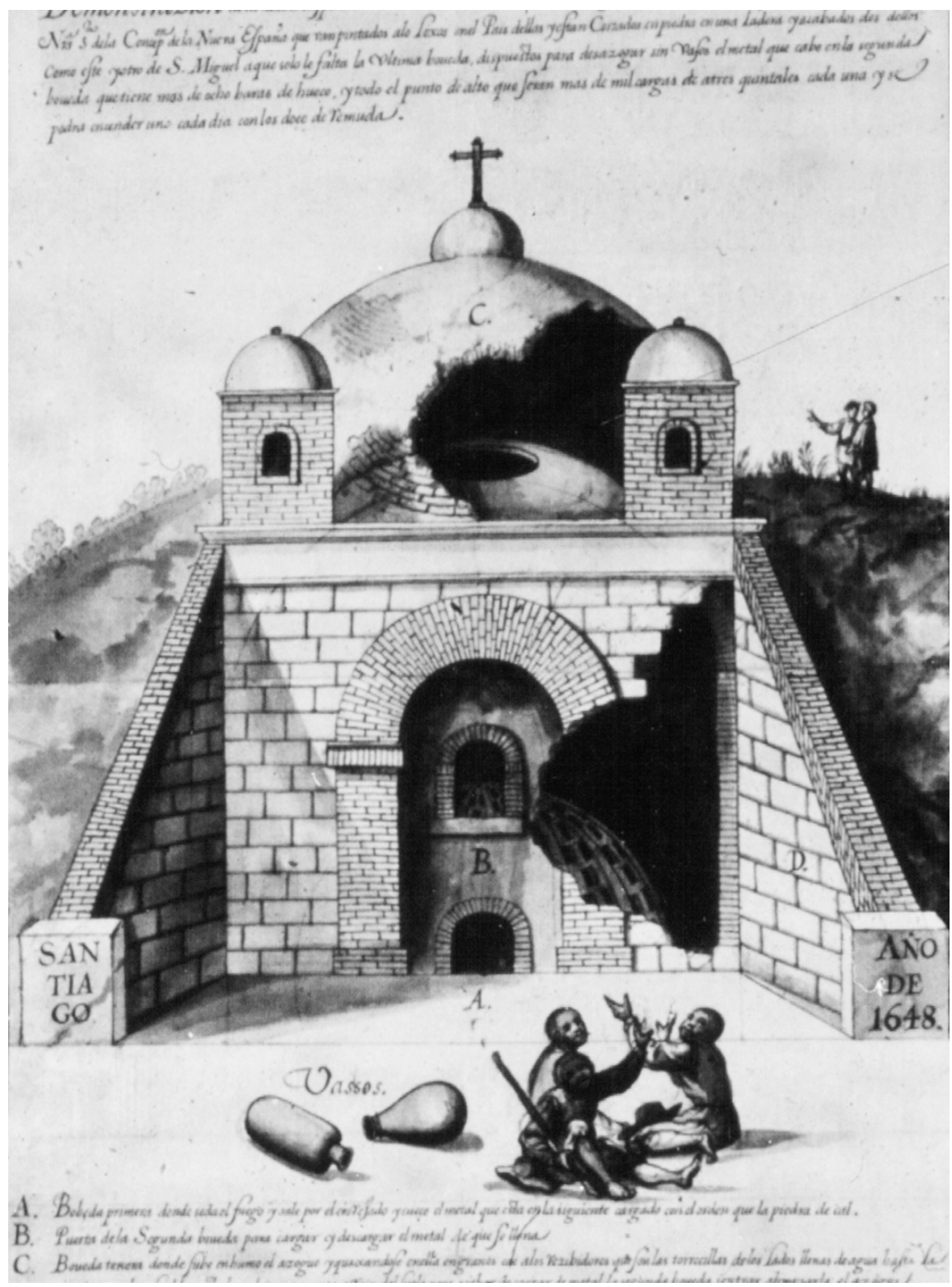

AGI, Mapas y Planos-México, 264, Minas, 54. 
El interés del virrey en el trabajo de su protegido se manifiesta en la visita que realizó a las minas. En ellas, el entonces aún alcalde del crimen le demostró a la máxima autoridad virreinal, "in situ", el beneficio mediante la preparación de los metales con "sal y magistral amasado y cocido en agua de jarillas o barillas". Posteriormente, en su libro, Berrio, además de incluir una consideración metalúrgica, también procedió a describir este método que contribuiría a una menor pérdida del azogue en el procedimiento de beneficio de la plata, el oro y otros metales. ${ }^{28}$

Durante sus años como miembro de los letrados y con cargos oficiales en la Real Audiencia, don Luis dedicó parte de sus actividades a lo que fue su principal interés y afición científica y técnica, la explotación y administración de minas de azogue y el manejo de ese material fundamental para el beneficio de la plata.

Hacia finales de 1645, quien era simultáneamente alcalde del crimen y juez administrador de las minas de la Nueva España, rescató e hizo trabajos de ensaye en las de azogue situadas en el distrito de Ajuchitlán, a cuarenta leguas de la ciudad de México hacia el rumbo de Michoacán. Dichas minas habían sido descubiertas y fundadas en 1630 por el dominico Alonso Paez y su hermano don Cristóbal de Paez y Montoya. Para sustentar el apoyo que el virrey Salvatierra daría a Berrio, le escribió al rey lo siguiente:

“...como me consta de los autos y memorial primero presentado por ellos (los hermanos Paez) en 16 de febrero de 1630 de que hacía demostración. Pidiendo me oyesen las partes y como quiera que esta materia siendo tan del servicio de S.M. estuviese olvidada y constándome por dichos Autos fechos en tiempos de los señores virreyes mis antecesores eran ciertas las dichas minas que se habían sacado en diferentes ensayos en ellas fechos a catorce onzas de azogue por quintal de piedra así en tiempo del Sr. Virrey, Marqués de Cerralbo como en el de Cadereyta que se hicieron en esta Ciudad en presencia de oficiales reales y otros ministros mando en Junta de Hacienda, dar diez mil pesos para la fundación a los primeros.... ${ }^{29}$

Poco después del descubrimiento de las minas de azogue, el dominico Alonso de Paez se había presentado ante la Audiencia para asegurar que, a través de las minas descubiertas, quería "hacer servicio al rey". ${ }^{30}$ Las actividades de Berrio en este trabajo minero, resumidamente, fueron las

28 Bargalló, Modesto: La Minería y la Metalurgia en la América Española durante la Época Colonial, México-Buenos Aires, 1955, págs. 167-170.

29 AGI, México, 264.

30 Ibídem. 
siguientes: El día 2 de enero de 1646 inició el trabajo de rescate de estas minas, el cual se fundamentó, precisamente, en la firma de una nueva petición por parte de sus originales concesionarios. Berrio presentó un informe el 2 de febrero de ese año, en el cual, no sólo justificó la riqueza en azogue de las minas, también solicitó, ya expresamente, lo conveniente que sería al servicio de la Corona la fundación de un "real y población" y los requerimientos económicos para realizarlo. Las peticiones de Berrio se centraron en disponer, cuando menos, de diez mil pesos para la fundación y rescate de las vetas que estuvieren cateadas y no cateadas y de la población que quedaría anexa al real y el poder contar con repartimiento de indios para el trabajo en la mina. Una vez que se vio su "Informe" en una o dos juntas, el 17 de febrero, el fiscal, la autoridad encargada de presentar las objeciones y ajustar las cuentas, desde luego, siempre a favor de la Real Hacienda y en contra de los solicitantes, opinó que Berrio procediese a la fundación a su propio costo y sin hacer cargo alguno a la Hacienda de su Majestad. Si bien a Berrio no debió satisfacer en nada esta decisión, la aceptó y tan sólo pidió que, a cuenta de los beneficios de la mina, se le facilitaran tres mil pesos para iniciar los trabajos. El 28 del mismo mes el virrey le otorgó, no sólo comisión para ausentarse, amparada en el cargo que ostentaba de juez administrador de las minas de la Nueva España, también le apoyó para que fundara el real y la población. Fue así como le autorizó a dar a los fundadores y pobladores las mismas prerrogativas que habían tenido quienes fundaran las minas de Huancavelica. Son interesantes las palabras que escribió el virrey a Berrio en su carta de comisión:

“...vaya y lleve en su compañía al dicho Fray Alonso Paez y a don Cristóbal Paez, su hermano, o a cualquiera de ellos al sitio de Ajuchitlán, donde haga y funde el dicho Real de minas de azogue y población de Nuestra Señora de la Pura y Limpia Concepción, en el sitio y lugar que más a propósito le pareciere, aunque sea el puesto donde fue el pueblo que se llamó de San Gregorio que hoy está despoblado y reparta a los pobladores, montes y aguas del servicio de las dichas minas y tierras que estuvieren baldías y sin dueños para sus sembrados y les conceda las franquezas, excepciones y libertades que se concedieron y están concedidas a los pobladores de Guancavelica, así para que gocen de mercados y tiangues francos y demás ventas ordinarias del trato del dicho Real, para los alimentos y vestir de sus pobladores como para que no tuvieren los que trabajasen en dichas minas según y como no tributan los que trabajan. En la de particulares que yo, en nombre de Su Majestad, se las concedo; y así mismo haga repartimiento de indios en los lugares donde no los hubiere, de salarios y pagas conforme le pareciere; que señale las ocupaciones de mayordomos azogueros, guardaminas y otras que convinieren; haga labrar las vetas que eligieren en el fondo y estados que para elegir continuación de las más 
ricas le pareciere, así en el dicho sitios que han señalado los descubridores, como siguiendo lo que ha propuesto; que haga así mismo los hornos de poder sacar azogue con menos costo...". ${ }^{31}$

Para la época el poder disponer del azogue fue de una enorme importancia para la economía de la metrópoli y de sus colonias. Se debió, por un lado, a la proliferación de los descubrimientos mineros en la región septentrional novohispana y, por otro, para mantener productivos los reales ya existentes. Sin duda que la Corona estaba fuertemente interesada en que la extracción del azogue en la Nueva España fuera exitosa. Fue por ello que la nueva y, aparentemente, rica mina rescatada por Berrio, como se ve por el texto anterior, recibió un significativo apoyo oficial dentro de las limitaciones de una economía española bastante exigua. Sin embargo, gracias a ese auspicio, la mina se mantuvo algún tiempo hasta que las autoridades conocieron que la riqueza de sus vetas no era tan espectacular como la había previsto el propio Berrio. Acerca del rendimiento de este mineral y del que correspondió a la concesión dada a Berrio contamos con un amplio y valioso análisis en el recién publicado trabajo del profesor Castillo Martos. ${ }^{32}$

Es interesante consignar que Berrio trabajó en las minas durante varios años y que, además del apoyo oficial, él mismo aportó parte de su salario como miembro de la Real Audiencia para el sostenimiento de los trabajos mineros. Así, sabemos que para el 4 de agosto de 1646 y desde las "Minas de la Limpia Concepción", Berrio envió lo que probablemente fue su primer informe de trabajo. En él da cuenta de la primera mina, llamada del Rosario, la que ya había sido trabajada por los indios; también de los inicios del trabajo en "las vetas ricas". Para hacerlo posible hubo necesidad de limpiar esta mina con gran riesgo, pero se realizó en más de 30 varas de largo, se instalaron lumbreras para iluminación directa y se limpiaron sus circunferencias. En la mina de la Santísima Trinidad se construyeron jacales y habitaciones para más de 60 personas y "dos hornos de azosegar y se compró herramienta por dos mil pesos".

Berrio proporciona en este "Informe" una brevísima descripción del entorno geográfico. Escribió que en el sitio existían bosques, la leña abundaba y se había encauzado el agua para el servicio de los propios indios y de la recién fundada población. Berrio procedió a invitar a los mineros y consejeros de minas de Tetela para visitar las nuevas y tener ocasión de

31 Ibídem y AGN, Reales Cédulas Duplicadas, vol. 17, exp. 147, fol. 104.

32 Véase, Castillo Martos, "Minería y metalurgia...". 
expresar su opinión sobre el avance de su comisión en la nueva fundación. Aquéllos, que respondieron a la invitación de Berrio, proporcionaron buenos informes sobre la labor hasta entonces realizada.

Durante su primera estancia en las minas, la labor de Berrio consistió en lo siguiente: la ampliación de las vetas, el descubrimiento de nuevas minas dentro del mismo circuito, la fundación de poblados y la instrumentación de una adecuada explotación del material, a través de la construcción de los hornos adecuados. Para esta tarea técnica, Berrio siguió las recomendaciones de Jorge Bauer, el llamado "Agrícola", expresada en su "De Re Metalica". A ello aunó sus propias experiencias técnicas. Según uno de sus escritos, los hornos los había fabricado "a su costa; con otro estilo de los de Huancabelica...el intento principal de los hornos por él hechos ha sido excusar vasos, cuya certeza y facilidad para todos ahorros es constante, pues al presente hay 40 mineros en Huancabelica que tienen a seis y a doce baños cada uno que sirven todos los días, con 24 de estos nuevos hornos se daría azogue a todo el Reyno sin que requieran de reparos ni hacerlos de nuevo continuamente como se hace en Huancabelica...." ${ }^{33}$ En este terreno señaló, constante y claramente, la diferenciación de sus procedimientos, especialmente los que se referían a la construcción de los hornos y que hacía que se distinguieran de los que se empleaban en las famosas minas peruanas. Inclusive, llegó a manifestar lo importante que sería el que trabajadores de aquella región vinieran a conocer sus procedimientos. Berrio nos introduce con más éxito en su técnica metalúrgica al entregarnos unos bellos dibujos de sus hornos. ${ }^{34}$

También es significativo en la personalidad de Berrio el hecho de haber conocido y reconocido el trabajo anterior de los naturales de la región en la explotación del azogue. Inclusive, en sus manuscritos menciona los términos con que se designaba al material en algunos idiomas indígenas: "los gentiles ya conocían el azogue y le daban nombre que era igual al castellano "agua de plata", en tarasco se le llamaba "icitayacata" y en cuitlateco "eumhali". ${ }^{35}$ En 1647 recibió apoyo del mismo rey, ${ }^{36}$ quien pidió a su virrey, el conde de Salvatierra, que enviara a Berrio los indios que

33 AGI, México, 264: “Cartas y Expedientes sobre la comisión de visitar las minas de azogue de Nueva España que tuvo don Luis Berrio”. En el tercero de sus manuscritos menciona, en relación a los hornos de Guancabelica, que éstos fueron tomados de la estampa de Agrícola: "en el libro 9. de Re Metálica de los cinco modos que pone de desazogar el 2o., pag. 316, de la impresión latina del año de 1556".

34 Proceden de AGI, Mapas y Planos-México, 264, Minas, 54 y 55.

35 AGI, México, 264, manuscrito fechado el 30 de abril de 1649.

36 AGN, Reales Cédulas Duplicadas, vol. 2, exp. 177, fols. 379r. y v. 
necesitaba para continuar la explotación de las prometedoras vetas. La decisión real estuvo avalada por la opinión del Consejo de Indias

Berrio no dejó pasar por alto la supervisión que hizo a las minas el oidor Gaspar Fernández de Castro. Sin embargo, serían los resultados de los ensayes que hizo este oidor, los que a la postre limitarían el apoyo oficial que se brindó a Berrio. En esa ocasión citó cómo el visitador se llevó buena impresión e información sobre la producción y que conoció, también, cómo esas mismas minas ya habían sido trabajadas por la gentilidad. Berrio escribió que la extensión por la cual se podían localizar las vetas era de, aproximadamente, un circuito de 50 leguas. ${ }^{37}$

Don Luis permaneció en la administración de las minas y en el real de la Concepción hasta 1650, año en el cual retornó a la capital a servir su plaza en la Real Audiencia. Su preocupación por el futuro de las minas lo plasmó en el "Informe" que rindió en 1651, en el cual pormenorizó sus actividades e insistió en la importancia de la extracción del azogue para la actividad minera de la Nueva España. Este trabajo está considerado, bibliográficamente, como su tercera obra, pero como he asentado anteriormente debe considerársela como la segunda. El "Informe" lo dirigió al virrey conde de Alva de Aliste e incluye, adicionalmente, una relación de las cartas que envió al Real Consejo de Indias sobre la materia del azogue y la minería. ${ }^{38}$ En sucesivos documentos-informes del propio Berrio correspondientes a los años de 1650 y 1651 continuó dando cuenta de lo importante que era para el desarrollo de la minería de la Nueva España mantener la extracción del azogue..$^{39}$

Durante 1650, desde luego, residiendo en la región de sus minas, recibió apoyo del virrey, conde de Aliste. La máxima autoridad del Reino de la Nueva España ordenó a los oficiales reales que ajustaran el estado de lo que se le había dado a Berrio en forma adelantada, a cuenta de sus salarios, hasta el mes de diciembre de ese año. De la cantidad que quedara debiendo "se le libren y paguen 4 mil pesos de oro común...dando fianza de vida a su satisfacción". Además se le exigió que todo el azogue que sacara lo enviará o entregará en la Caja Real que lo tuviera a su cargo donde se le abonaría,

37 AGI, México, 264.

38 Informe al Excmo. Señor Don Luis Henriquez de Guzmán, Conde de Alva de Aliste y de Villaflor....Exmo. Señor. Sobre el beneficio de la Plata, conservación de Azogues y mezcla de Antimonio, etc... El Licenciado Don Luis Berrio de Montalvo, Alcalde del Crimen más antiguo de esta Real Audiencia de México, Auditor General de la Guerra, y juez de Minas desta Nueva España. Digo, que por Cedulas de su Magestad, etc.

39 AGI, México, 264, manuscrito fechado en la ciudad de México el 5 de marzo de 1654. 
según su valor "en la cantidad y forma conveniente a cuenta de su débito...". ${ }^{40}$ Durante ese mismo año, Berrio en sus escritos hace referencia a sus continuadas y buenas experiencias en la obtención de oro en las minas de San Juan de los Llanos. En alguna ocasión estuvo presente y atestiguó la extracción del aurífero metal, el visitador general de la Nueva España, el oidor de Granada don Pedro de Gálvez. ${ }^{41}$

Ante la insistencia oficial que le exigía retomar su plaza de letrado en la Real Audiencia, Berrio regresó a la ciudad de México, muy posiblemente durante 1651. Lo que sí es un hecho es que, a su llegada, rindió informe de todo lo sucedido en las minas de azogue que explotaba. Permaneció en la capital sirviendo su plaza de alcalde del crimen y cumpliendo otras comisiones del virrey, pero mantuvo su fuerte convicción de que se podía extraer buena cantidad de azogue de los minerales para el beneficio de la minería argentífera.

Una vez que se reestablecidó en la capital novohispana rindió un nuevo informe acerca de la situación en la cual había dejado las minas de azogue. En su escrito precisó que llevaba año y medio sirviendo su plaza de alcalde del crimen y que:

" hace más de cinco años y medio que ha corrido y corre por mi cuenta el descubrimiento, población y gasto de las minas de azogue con costa de más de diez mil pesos en cada un año para darles estado de poderse sacar azogue en tres Reales de Minas que a tres y cuatro leguas de distancia unos de otros he poblado, sustentando y pagado salarios a más de sesenta personas de trabajo y sus familias. Las minas son fijas y sus vetas de ley de azogue que los metales puros recién sacados rinden (como en otro lado he dado cuenta a S.M.)...y la perpetuidad de estas minas está asegurada en su muchedumbre, en hallarse descabezadas las vetas desde lo alto de los cerros hasta sus faldas y hecha labor y mina en cada una de suerte que sirven de socavones las unas de las otras y se saca con facilidad el metal...tengo descubiertas otras muchas que corren al norte que poblaré con lo del salario de la sala que salen de la Audiencia..... ${ }^{42}$

Para 1652 escribió un nuevo documento. En él dio cuenta de todas las minas que tenía descubiertas y pidió, de nuevo, ayuda para continuar en la labor de extracción del azogue, ya que para entonces se le habían retirado de 1650 .

40 AGN, Reales Cédulas Duplicadas, vol. 15, exp. 157, fol. 111v., del 12 de diciembre

41 AGI, México, 264.

42 AGN, Reales Cédulas Duplicadas, vol. 15, exp. 157, fol. 112r., del 12 de diciembre de 1650 . 


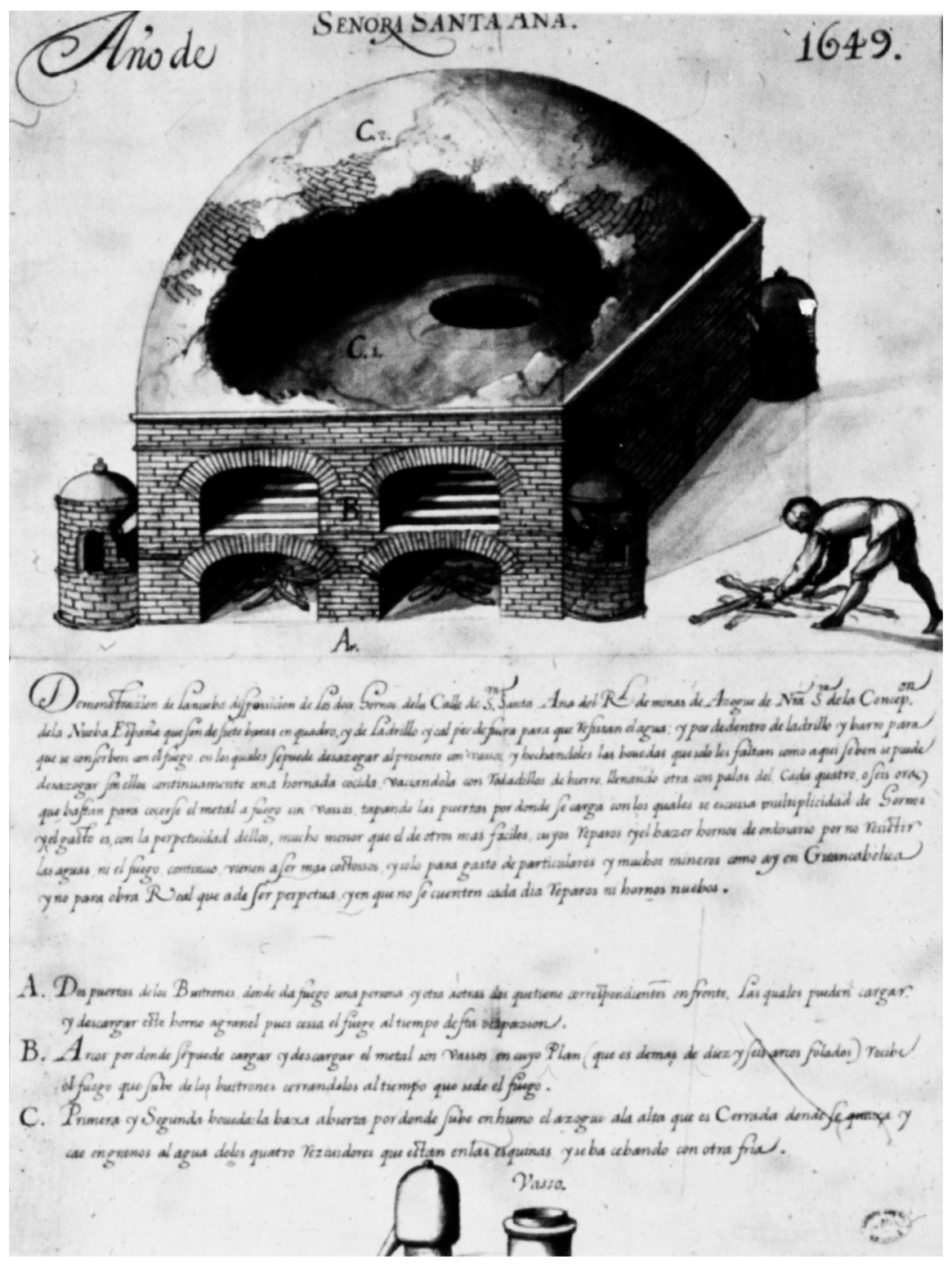

AGI, Mapas y Planos-México, 264, Minas, 55. 
las encomiendas de indios destacados en el trabajo de las minas de azogue. Berrio mencionó que en las inmediaciones de La Concepción había descubierto más de doce minas buenas, entre ellas la de San Nicolás. Otro mineral quedó situado a cuatro leguas de distancia; lo nombró Santiago Compostela, sitio que mandó poblar y en donde levantó las oficinas necesarias para la saca del azogue. Con rumbo sur y a dos leguas de La Concepción, existía la mina de San Gabriel Axuchitlán o Ajuchitlán, de donde se habían sacado ya 40 quintales de azogue.

Por su interés personal en continuar figurando como empresario minero y al verse imposibilitado para regresar de inmediato al sitio de las minas, pidió ayuda al rey. Fue así como, temeroso de que se despoblase el real recién fundado, solicitó, directamente, a la Corte le ayudase otorgándole otra plaza en la Real Audiencia, ya que con la que tenía de alcalde del crimen le era imposible sustentar las minas y su casa. Explicó que había dejado persona comisionada para que arrendara las minas y las administrara, pero al parecer este arreglo no le había sido útil, ya que, desafortunadamente, su comisionado había fallecido. Sin responsable en el poblado y las minas, el despoblamiento de la región fue casi inmediato, inclusive se descuidaron las casas y algunas de ellas fueron incendiadas.

La respuesta a esta solicitud fue totalmente negativa. Por un lado, la metrópoli opinó que se continuara la explotación del azogue. Por el otro, no aceptó que fuera a costa de la Real Hacienda y tampoco que Berrio tuviera un ascenso, obligándole a permanecer en su misma plaza. Sin embargo, se le concedió un pequeño aliciente: se acordó que don Luis podría conservar y explotar las minas, aplicándosele para su trabajo a los delincuentes y los "bárbaros" del Cerro Gordo. Esta propuesta fue recusada por Berrio, quien, poco tiempo después, logró que los indios que quisieran pudieran trabajar por su voluntad y desde luego con paga de sus salarios.

$\mathrm{Su}$ insistente reclamo de ayuda le fue nuevamente aprobado por el virrey Francisco Fernández de la Cueva, duque de Alburquerque, en 1653. Berrio había solicitado que se le proporcionaran cuatro mil pesos a cuenta de sus salarios como alcalde del crimen, así como lo que le correspondiere como justicia mayor que había sido de las minas de Tetela. El virrey ordenó a los oficiales reales que procedieran a ajustarle las cuentas a Berrio en lo concerniente a sus adeudos como justicia mayor. En consideración a los muchos años que había servido a la administración virreinal en tareas tan importantes al servicio real, acordó un adelanto de dos años en sus sueldos de la plaza de alcalde del crimen. Se le reconoció haber pagado con los azo- 
gues procedentes de sus minas los préstamos anteriores y por ello existía ya una cierta garantía para volver a apoyarlo..$^{43}$

Berrio se vio obligado a servir su plaza durante los siguientes tres años y, durante su estancia en la capital, finalmente, pudo nombrar en las minas un mayordomo. Pero, al igual que en la ocasión anterior, este arreglo no dio buenos resultados. Sin ocultar su interés primordial, el minero, Berrio, si bien solicitó licencia en su plaza, el cambio de virrey le fue adverso y permaneció como alcalde en la Real Audiencia. Para ese tiempo don Luis reconoció que su ausencia de las minas había repercutido en grandes daños en la explotación del azogue y que después que se le habían negado los trabajadores y adjudicado delincuentes, finalmente se le había autorizado a continuar los trabajos, pudiendo emplear esclavos. Fue en esa misma ocasión en la cual solicitó al rey darle licencia "para poder casar en cualquiera del distrito de esta Audiencia". Berrio argumentó en su favor haberse dado ya otros casos similares de miembros de la Real Audiencia que habían contraído matrimonio dentro de la jurisdicción de esa institución, añadiendo en su favor que llevaba ya más de dieciocho años de servicios en la Audiencia. Esta petición está fechada en México el 5 de marzo de $1654 .{ }^{44}$ Dos años después, en 1656, se le autorizó a reiniciar la administración de las minas de azogue; en esa fecha procedió a escribir un nuevo "Informe" de sus actividades y de la importancia de continuar la explotación del azogue. No existe constancia de que este trabajo haya sido publicado, pues sólo conocemos el manuscrito.

A pesar del inicial apoyo que le brindó a Berrio el duque de Alburquerque, algún tiempo más adelante, 1656, se lo retiró. El virrey asentó que los expertos habían opinado desfavorablemente en relación a las posibilidades de extracción del material, en forma contraria a como lo había argumentado y probado Berrio. Ante esta situación el alcalde del crimen solicitó, en julio de 1656, permiso para trasladarse a España a defender su posición y sus argumentos mineros; sin embargo, no hay constancia de que hubiera emprendido tal viaje. Lo que sí está documentado es que, precisamente, en ese año, el 13 de septiembre, el rey le concedió, en recompensa a sus servicios, el cargo de oidor. Entró en su posesión el 5 de mayo del siguiente año y lo disfrutó hasta su muerte en $1659 .{ }^{45}$

43 AGN, Archivo Histórico de Hacienda, vol. 755, 1609-1773, año de 1653, fols. 23r. y v.

44 AGI, México, 264, "Cartas y Expedientes sobre la comisión de visitar las minas de azogue de Nueva España que tuvo don Luis Berrio".

45 AGI, Indiferente, 120, n. $^{\circ} 101$. 
Después de su muerte, las minas que había explotado seguramente cayeron en abandono. No hay noticia de que hubiera continuado su tarea alguno de sus hijos. Para 1657 el mayor de ellos, don Luis, tenía el cargo de capitán, y en esa fecha solicitó al virrey le concediera la alcaldía mayor de "Atrisco con agregación del partido de Tuchimilco", área cercana a la ciudad de Puebla. ${ }^{4}$ Algunos años más tarde la extracción del azogue en la mina de Berrio fue puesta en circulación. El ensayador y balanzario de las cajas de minas de la ciudad de México, Martín López, ofreció fomentar y poner en operación, a su costa, las minas de azogue de "San Gregorio que están en la jurisdicción de Tetela y descubrió Don Luis de Berrio". El nuevo interesado previamente había hecho ensayos de la posible producción de azogue y pidió que se le dieran ciertas concesiones para trabajarlas. En 1663 se le autorizó para que las volviera a explotar por su cuenta y al mismo tiempo conservara su puesto de ensayador y nombrara su teniente en las minas, como se le había concedido a Berrio. Se previno que ningún vecino podría obstruir su trabajo y que durante los cuatro primeros años del asiento o estanco que estaba celebrando, no pagaría diezmo como minero y se le tomaría cada quintal de azogue a razón de 82 pesos. Durante los siguientes años el precio sería de 62 pesos y tendría ya la obligación de diezmar. En la entrega de su asiento se le recomendó que tuviera muy presente una correcta explotación, pues si bien las vetas que se habían descubierto no habían sido muy ricas, podrían encontrarse otras más abundantes. Se dejó claramente especificada la importancia y conveniencia de una abundancia del material, tanto para la "Provincia" como para la Real Hacienda. ${ }^{47}$

El letrado-técnico recibió en repetidas ocasiones el reconocimiento de la Corona por su trabajo en el descubrimiento, administración y explotación de las minas de azogue, ya que, sin duda alguna, aportó utilidades a la Real Hacienda. Para Berrio su actividad técnica fue la que ocupó su principal interés; sin embargo, dividió correctamente sus tareas para cumplir con los dos papeles socio-profesionales que le tocó desempeñar. En su caso, su actividad como técnico fue la que le proporcionó los requerimientos necesarios para su promoción dentro del grupo profesional de los letrados. Fue así como el rey le otorgó su última promoción, que consistió en su nombramiento en el cargo máximo de los letrados en Indias, el de oidor; lo hizo en reconocimiento a sus labores en la minería y meta-

46 AGN, Reales Cédulas Originales, vol. 19, exp. 237, fol. 133v., del 8 de junio de 1657.

47 Ibídem, vol. 7, exp. 141, fol. 2, del 4 de junio de 1664. 
lurgia y, desde luego, a las aportaciones que se derivaron de ellas para la Real Hacienda.

Ya como oidor, recibió una comisión del rey, fechada el 17 de febrero de 1657, para trasladarse a Guadalajara y averiguar el comportamiento y procederes de uno de los oidores de aquella audiencia. No tenemos certeza de que Berrio hubiera realizado esta misión, ya que el rey la concedió también en segundo lugar a uno de los alcaldes del crimen. Sea que haya participado directamente, sea que sólo haya recibido la comisión, lo que es destacable es el hecho de que, como oidor, tuvo el reconocimiento real. ${ }^{48}$

\section{Sobre su obra impresa}

De acuerdo a la bibliografía localizada, publicó su primera obra en $1634{ }^{49} \sin$ embargo, como ya dijimos arriba, resulta difícil aceptar que haya sido en ese año, ya que en su publicación da cuenta del beneficio de las minas de Taxco, lo que presupone un conocimiento previo de su funcionamiento y un manejo de la temática minera, mismo que no poseía antes de su traslado a la Nueva España. Me inclino a suponer que se trata de un error bibliográfico y lo que se ha tenido por su primera obra, en realidad, sea la misma que publicó en $1643^{50}$ y que hasta ahora se ha considerado, dado lo poco estudiado del personaje, como su segunda publicación. La dedicó al virrey conde de Salvatierra.

Su contenido no se limita al aspecto estrictamente técnico: incluye conceptualización filosófica y responde a esa vinculación entre el letrado, con su bagaje cultural humanístico, y el especialista en alguna de las técnicas, en su caso, más que la minería propiamente dicha, la metalurgia. De acuerdo a Maffei y Rúa Figueroa, ${ }^{51}$ se trata de una obra especializada y "rarísima" que comprende 20 capítulos y que se inscribe en la corriente que buscó perfeccionar los métodos de beneficio de patio, de cajones y el más cercano a su tiempo, el del "beneficio por cazo y cocimiento" a través del uso de azogue especificado por Alonso de Barba. Según la obra consulta-

48 Ibídem, vol. 27, exp. 162, fols. 436-438v., del 17 de febrero de 1657.

49 Informe sobre las minas de Tasco y modo de beneficiarlas....

50 Al Exmo. Señor don García Sarmiento de Sotomayor y Luna Conde de Salbatierra, Marqués de Sobrosso, Señor....Su Virrey, Lugartheniente, Gobernador y Capitán General desta Nueva España...

51 Maffei, Eugenio, y Ramón Rúa Figueroa: Apuntes para una Biblioteca Española de libros, folletos y artículos impresos y manuscritos relativos al conocimiento y explotación de las riquezas minerales y a las ciencias auxiliares, Madrid, 1871, 2 volúmenes. 
da, el trabajo de Berrio se encuentra en la Real Academia de la Historia y los 20 capítulos de la obra son los siguientes:

1. - Calidades de la Tierra y demás elementos de que se forman los Minerales.

2.-Curso del Sol que los continúa.

3.-Efecto del vapor en la formación de los Metales.

4.- -Unión de los elementos en la misma formación de los Minerales, de la Tierra y sus Metales.

5.-Especial formación de los Metales que se juntan en la Tierra y piedras minerales.

6.-Antiguo beneficio de la fundición de los Metales.

7.- Por que antes se reconoce el de la minería de fundición y azogue.

8.-Espíritus minerales de que se forman los Metales y sus vetas.

9.-Calidades del azogue, su conocimiento y preparación.

10.-Del azufre y su mortificación.

11.-Tercero espíritu mineral, o sales de nitro, de que se forman las vetas.

12.-Cuarto espíritu mineral terrestre y formación del vidrio fundible.

13.-Cuerpos minerales, sus colores, calidades y beneficios.

14. - Causas del consumido de azogue y liga de plomo y de ambos beneficios.

15.-Continúanse las causas del consumido, por argumentos del beneficio del oro al de la plata.

16. - Calidades y beneficios de los metales, desde el menor al mayor, de los de plomo y estaño.

17.-Calidades y beneficio del hierro.

18. - Calidades y beneficio del cobre.

19.-Calidades y beneficio del oro.

20.-Calidades y beneficio de la plata.

En el inicio de la obra aparece la "Provisión", en la cual se confirió a Berrio el encargo de las experiencias del nuevo beneficio que habían propuesto Pedro García de Tapia y Pedro de Mendoza Meléndez. El oidor, Berrio de Montalbo, especializado en los asuntos de la minería, había observado y supervisado los experimentos que los mineros locales realizaron en Taxco, un claro ejemplo de la estrecha vinculación que, en ocasio- 
nes, se dio tan acertadamente en el desempeño de papeles y roles profesionales en dos de los estamentos más significativos de la época, el de los letrados y el de los técnicos.

\section{Jerónimo Bezerra}

Este autor de obra técnica ${ }^{52}$ publicó su primera aportación dentro del estamento de los médicos-cirujanos. Fue en ese ámbito científico autor de una muy interesante obra en que se incursiona, por primera vez, en la academia novohispana en el terreno de la psicología. ${ }^{53}$ A través de este libro Becerra trata de explicar el surgimiento de actividades intelectivas, sensitivas y emotivas y vincularlas con la composición y funcionamiento de los cinco sentidos externos y materiales. Bezerra inscribe su obra médica en la "Anathomia Philosóphica", pero como él mismo escribe no pretende ser un experto, ya que reconoce que para ello "son bastantes los escritos del Maestro Juan de Valverde”. Si bien Bezerra no fue médico de profesión, sí se le ha reconocido un amplio conocimiento de la materia que trató en su ya clásica obra. Su vinculación con la técnica procede de su papel como ensayador en la Casa de Moneda de la capital novohispana y de su relación con un ensayador, seguramente de mayor posición que él mismo en el estamento de los técnicos, quien le solicitó una "Breve relación del ensaye de plata y oro".

En cuanto a los escasos datos de su vida personal conocemos que Bezerra tuvo un hermano, Pedro, quien también ocupó el oficio de teniente de ensayador y fundidor en la misma institución. Debió haber sido mayor que Jerónimo, ya que en ocasión de enfermedad del primero, le fue autorizado al menor "ocupar su lugar y usar y ejercer los oficios". ${ }^{54}$ Contamos también con la localización de su partida de defunción. En ella se menciona que falleció el 15 de febrero de 1677 y se le enterró en la catedral de la ciudad de México. Se señala que estaba casado con doña María Munguía

52 Breve relación del ensaye de plata y oro. Escríbela Geronymo Bezerra, Ensayador de la Real Casa de la Moneda de México. A pedimento de el capitán Ioseph de Quezada y Cabreros, Ensayador examinado de Plata y oro.

53 Lleva el título: Estudioso discurso philosophica anathomia, y theatro ingenioso de los órganos y sentidos interiores, y exteriores del hombre. Escribiólo Gerónimo Bezerra, Ensayador de la Real Casa de la Moneda de México, y lo dedica al capitán Alfonso de Valdés. En México. En la Imprenta de Agustina de Santiestevan, y Francisco Rodríguez Lupercio. Año de 1657.

54 AGN, Casa de Moneda, s/f. 
y que testó ante el escribano real Cristóbal de Tobar el primer día del mismo mes y año en que falleció. Fueron sus albaceas su mujer y Manuel de León y en su testamento dejó establecida la celebración de 500 misas por su alma. A la fecha de su fallecimiento tenía su domicilio "frontera de la portería de Santa Inés". ${ }^{5}$

Como se puede apreciar se trató de un singular personaje con un doble papel científico en el campo de los saberes médicos y práctico en el de la metalurgia.

El siguiente personaje es el último de los autores del siglo XVII vinculado con la minería. Se trata de:

\section{Juan del Corro y Segarra}

Su obra es un libro que salió a la luz pública en una segunda edición, incidentalmente, en la Nueva España en el año de 1677:56 la primera fue impresa en Lima en el mismo año y lleva un título mucho más largo. ${ }^{57}$ Es posible que la edición novohispana corresponda a uno de los dos manuscritos que describe el destacado bibliógrafo José Toribio Medina. ${ }^{58}$

Interesante y fructífera ha sido la localización documental en el Archivo General de Indias de Sevilla y que nos permite proporcionar, por primera ocasión en la historia de la minería, información sobre este autor; entre otros datos, hasta ahora inéditos, su nombre completo, su genealogía y rasgos de su actividad minera.

55 Archivo Parroquial de la Catedral de México, Primer Libro de defunciones de Españoles, 1671-1680, Libro de los difuntos españoles de la feligresía de la Santa Iglesia Metropolitana de México que empieza desde fecha 14 de noviembre de 1671 en adelante. Fol. 195v. Información localizada por la licenciada en historia, Rosalba Tena V, becaria del proyecto.

56 Forma del nuevo beneficio de metales de plata.

57 Instrucción y forma de beneficiar metales de plata, de modo que se saque toda sin perder cosa alguna de las que hasta agora se perdía cuyo gran aumento se logra con gran brevedad y ahorro de tiempo y con muy poco consumo de Azogue, cuyo secreto y nuevo agente que obra con tanta eficacia descubrió y redujo a práctica en el Cerro del Potosí y toda su Ribera, Don Juan del Corro y Segarra por el año de 1676 con asistencia del Licenciado Don Bartolomé González Poveda, Presidente de Charcas, que en carta de 3 de junio de dicho año participó los admirables efectos experimentados al Señor Virrey del Perú y remitió testimonio de autos y tanto de la instrucción que es la siguiente: Forma del nuevo beneficio de metales de plata por el Capitán Juan del Corro.

58 Según José Toribio Medina en su Biblioteca Hispano-Americana (1493-1800), Santiago de Chile, MCMII, tomo IV, pág. 403, hubo dos manuscritos, tal vez previos al impreso, de uno de ellos se dice que: "A fines del siglo XVIII poseía otro el Diputado general de Minería en Méjico, Don Juan Manuel Valcarce con el título: Método de beneficiar los minerales argentíferos en lugar del mercurio con la pella de plata”. El otro manuscrito era: Nuevo método de beneficiar la plata. 
Don Juan del Corro y Segarra fue natural de Siporo, en la Provincia del Potosí, en Perú y, gracias a la concesión del hábito de caballero de la orden de Calatrava, proporcionó sus antecedentes familiares. ${ }^{59} \mathrm{El}$ expediente se inicia con el otorgamiento del hábito:

"El Rey. Con decreto de nueve de noviembre del año pasado de 1679 en consideración de lo que Don Juan del Corro y Segarra ha servido en el beneficio de las minas que tiene en la jurisdicción de la Villa de Potosí, le hice merced de hábito de órdenes militares para su persona y porque ha elegido el de la orden de Calatrava, os mando..."

De la genealogía que presentó para iniciar los trámites del otorgamiento del hábito, entresacamos los siguientes datos. Fueron sus padres, "el capitán Juan del Corro, "Veinte y Cuatro" del Cabildo de la Villa del Potosí, natural de Mérida en los Reynos de España y de doña Antonia de Zegarra y Valverde, natural de la ciudad de Arequipa en el Perú, los dos fueron vecinos de la Villa del Potosî". Por la línea paterna sus antepasados fueron extremeños y por la materna, su abuelo y bisabuelo, naturales de Arequipa y ambos casados con mujeres madrileñas, en tanto que sus tatarabuelos maternos provinieron de la capital andaluza, Sevilla.

El personaje ocupó el cargo de capitán en el virreinato del Perú y propietario, sin duda, por herencia, de minas en la provincia del Potosí. Fue en ella en donde se ocupó del beneficio de la plata y de acuerdo a Maffei y Rua Figueroa fue Corro quien, hacia 1674, inventó un nuevo beneficio de los minerales empleando la pella de plata en lugar del mercurio sólo en la amalgamación, sistema que en el momento produjo un gran entusiasmo, pero que pronto decayó, no faltando mineros celosos de aquel entusiasmo, que sostuvieron que Corro no fue el inventor de aquel procedimiento y que era ya conocido por los primeros azogueros.$^{60} \mathrm{Sin}$ embargo, la sociedad peruana recibió con gran beneplácito el descubrimiento que anunció Corro y fue ampliamente celebrado con procesión religiosa y fiestas populares según narra la reseña que realizó su contemporáneo Lorenzo Felipe de la Torre. ${ }^{61}$

Si bien el peruano Juan del Corro perteneció a la misma actividad de explotación minera que Berrio de Montalbo; no puede ser vinculado con el estamento novohispano que aquí analizo, ya que no existe documentación alguna que permita pensar que estuvo relacionado con esa sociedad.

59 Proceden de Archivo Histórico Nacional, Órdenes Militares, 297, expedientillo 11051, 1677-1710, y Órdenes Militares,165, expediente 673, 1680.

60 Mafei, Figueroa, Biblioteca Minera Española... t. II, págs. 170-171.

61 Ibídem, pág. 171. 


\section{Rasgos Estamentales y de Ciencia Nacional de los Técnicos Mineros}

Las características de los integrantes del grupo de los técnicos, quienes ejercieron su labor en la Nueva España, Berrio y Bezerra, y que se relacionaron y aportaron conocimientos a una de las actividades económicas más importantes de la época colonial, están fundamentadas en el conocimiento de su desempeño profesional y su ubicación contextual. Berrio de Montalbo nuevamente, como lo fueron los letrados-técnicos que intervinieron en las obras del desagüe de la capital novohispana, representa la estrecha relación entre dos estamentos, el de los letrados y el de los técnicos. Bezerra, a partir de su desempeño profesional como técnico ensayador, se vincula, por un lado, con los médicos y, por el otro, con los mineros. En ambos casos pertenecieron a instituciones de control profesional y social, la Real Audiencia y la Casa de Moneda, en ellas obtuvieron reconocimiento a su trabajo y la posibilidad de vincularse con otros estamentos.

Estos dos autores que ejercieron en la Nueva España compartieron y mantuvieron corrientes de pensamiento que les permitieron continuar líneas de conocimiento teórico-prácticas y, consecuentemente, tuvieron vinculación con los integrantes de la misma actividad profesional y obtuvieron su reconocimiento. Se insertaron en la sociedad en que transcurrió su vida profesional; en ella fueron reconocidos, en especial, por sus contribuciones a la búsqueda de métodos teórico-prácticos para un mayor beneficio de la explotación minera.

En cuanto a su aportación al incipiente proceso de constitución de una ciencia nacional fueron capaces de introducir y difundir conocimientos en una sociedad en desarrollo, y adaptaron sus conocimientos teórico-prácticos a través del reconocimiento e incorporación de los elementos técnicos que anteriormente se habían producido en el propio contexto. Y tomaron conciencia social de la necesidad de contribuir con sus conocimientos y su ejercicio profesional al desarrollo de esta importante estructura económico y social. 